

\title{
Exploring communication between social workers, children and young people
}

\author{
Winter, K., Cree, V., Hallett, S., Hadfield, M., Ruch, G., Morrison, F., \& Holland, S. (2016). Exploring \\ communication between social workers, children and young people. British Journal of Social Work, 47(5), 1-30. \\ https://doi.org/10.1093/bjsw/bcw083
}

\section{Published in:}

British Journal of Social Work

\section{Document Version:}

Peer reviewed version

Queen's University Belfast - Research Portal:

Link to publication record in Queen's University Belfast Research Portal

\section{Publisher rights}

(C) The Authors 2016. Published by Oxford University Press on behalf of The British Association of Social Workers. All rights reserved. This is a pre-copyedited, author-produced PDF of an article accepted for publication in The British Journal of Social Work following peer review. The version of record is available online at doi: $10.1093 / \mathrm{bjsw} / \mathrm{bcw} 083$.

\section{General rights}

Copyright for the publications made accessible via the Queen's University Belfast Research Portal is retained by the author(s) and / or other copyright owners and it is a condition of accessing these publications that users recognise and abide by the legal requirements associated with these rights.

\section{Take down policy}

The Research Portal is Queen's institutional repository that provides access to Queen's research output. Every effort has been made to ensure that content in the Research Portal does not infringe any person's rights, or applicable UK laws. If you discover content in the Research Portal that you believe breaches copyright or violates any law, please contact openaccess@qub.ac.uk. 


\begin{abstract}
A key issue for the social work profession concerns the nature, quality and content of communicative encounters with children and families. This article introduces some findings from a project funded by the Economic and Social Research Council (ESRC) that took place across the United Kingdom between 2013 and 2015, which explored how social workers communicate with children in their everyday practice. The Talking and Listening to Children (TLC) project had three phases: the first was ethnographic, involving observations of social workers in their workplace and during visits; the second used video-stimulated recall with a small number of children and their social workers; and the third developed online materials to support social workers. This paper discusses findings from the first phase. It highlights a diverse picture regarding the context and content of communicative processes; it is argued that attention to contextual issues is as important as focusing on individual practitioners' behaviours and outlines a model for so doing.
\end{abstract}

Key words: social workers; communication; children and families; ethnography; visits. 


\section{Introduction}

At the time of writing, and with the notable exception of work by Ferguson (2009, 2016) and Broadhurst and Mason (2014) there is little social work research on the 'real world' of the social worker visit, whether to the family home or anywhere else. This article introduces findings from a cross-UK research project funded by the Economic and Social Research Council (ESRC) that took place between 2013 and 2015. The Talking and Listening to Children (TLC) project set out to explore how social workers communicate with children and young people in their everyday practice. It had three phases: the first was ethnographic, involving observations of social workers in their workplace and during visits; the second used video-stimulated recall with a smaller number of children and their social workers; and the third involved the development of online materials to support social workers. Given the size of the dataset and the rich, thick, detailed descriptive content therein, this article is confined to a discussion of the first phase of the study. Contextual and methodological factors relating to the research project are discussed, before moving on to a consideration of the findings.

\section{The policy and practice context of contemporary social work practice}

In the United Kingdom, the discourse around the deficiencies in social worker communicative processes with children has been shaped, in the main, by the findings of a number of inquiry reports that have shown successive failings, seemingly impenetrable to change (Laming, 2003, 2009). Various reviews (Ofsted, 2011; Winter, 2011; Munro, 2010, 2011a, b) have all indicated a common and enduring set of themes, namely that the child has not been seen frequently enough, has not been engaged with to ascertain their views and feelings and has got lost in 
what is an over-focus on parents, at the expense of children. In ascertaining to what extent and why these shortcomings in basic communicative processes may exist, there is a body of research that highlights systemic and contextual issues, ranging from high caseloads and staff turnover to the over-reliance on technical and bureaucratic aspects of the job (Broadhurst et al., 2010; Munro, 2010, 2011a, b; Winter, 2011). A related body of work is workforce capacity and capability. The work of Lefevre (2013) and Luckock and Lefevre (2008), in particular, indicates gaps in knowledge and skills for trainee social workers and weaknesses in the current training provision. These deficits appear to continue once qualified, with social workers reporting that they do not feel adequately equipped to communicate with children and families in appropriate and meaningful ways because of a lack of time, tools and emotional support (Munro, 2011, a, b; Ruch, 2007; Winter, 2011; Warner, 2015) leading to concerns about 'burn-out' and defensive, disengaged practice (Winter, 2011; Winstanley and Hales, 2014).

In this context, changes are afoot in the UK, especially in light of the Munro review $(2010,2011 a, b)$. These changes seek to reclaim the importance of the relationship between social workers and children and significance of 'face-to-face practice' (Featherstone et al., 2011; Broadhurst and Mason, 2014; Ruch et al., 2010; DfE, 2014). The changing landscape is evidenced in England through the Department for Education Children's Social Care Innovation programme (http://springconsortium.com) which, with its emphasis on innovation and the redesign of service delivery in children's social work, is funding a number of pilot programmes that seek to re-balance the competing demands bureaucratic functions and opportunities for face-to-face engagement. In Scotland, child protection is also 
under review. Social work research is also becoming more concerned with eliciting the detailed dynamics of these communicative encounters either through qualitative methods (Ferguson, 2016; Broadhurst and Mason, 2014) or quantitative methods in which the quality of the relationship (or working alliance) between social worker and service user and levels of perceived engagement have been measured (Westlake, 2015; Killian et al., 2015).

\section{Research questions, methodological approach and methods}

Emerging from a concern to better understand how and in what ways social workers facilitate communication with children and young people in different contexts, the TLC project had four key research questions: What are social workers observed to do when they communicate with children and young people in a range of settings (including those living at home and in foster care or residential care) and with a range of aims (including child protection, assessing need and promoting well-being)? How do practitioners experience and understand their communication? How do children and young people experience and understand their relationships with social workers? What factors best facilitate communication between social worker practitioners and children and young people?

To address these questions, the project was, as noted, designed with three phases and received ethics approval from the participating universities, local authority social work departments and/or Health and Social Care Trusts that agreed to be involved in the study. Ethical advice from the pre-funding stage onwards was provided by a research advisory group, comprising care-experienced young adults, some of whom have also received social services involvement as young parents, and who are 
trained in research methods. Adopting an approach in research with social workers, children and young people and families where their communicative encounters were observed 'in action' carries with it a number of potential benefits and risks (Haight et al., 2014; Broadhurst and Mason, 2014; Westlake, 2015). The hoped-for benefits were to gain a full appreciation of the nuanced, contingent and complex nature of communicative encounters. Anticipated risks included families: feeling unable to say 'no' to the researcher's presence; not fully understanding why there was a researcher present; and having their opportunities to engage with their social worker disrupted by the presence of a researcher. For social workers, there was a concern that they might feel overburdened by being involved in the research and that they might experience anxiety by having what is essentially a 'private' aspect to their practice exposed to the observations of a researcher (Ferguson, 2016; Westlake, 2015).

Reflecting similar research (Broadhurst and Mason, 2014; Ferguson, 2016; Westlake, 2015) these issues were addressed by a detailed ethical protocol premised on the exercise of participant choice and control, whenever possible, and reflected the principles of ethical research practice as 'reciprocal, relational and responsive (Shaw and Holland, 2014, p. 118). Examples included social workers being invited to opt into the research and also being invited to identify families thought to be suitable for involvement in the project. Information about the research and consent to be involved was relayed to the families by the social worker. The families too had to choose to opt in. In relation to data collation, further choice was inbuilt in that social workers could decide not to have their conversations with researchers digitally recorded; families could decide not to have the researcher 
engaged in note-taking during the visit; and researchers could decide that on some visits it was not appropriate to take detailed notes during the visit itself, but rather to record these immediately afterwards.

In phase one, three researchers were located in eight social work teams across the UK (two in each nation) for a period of approximately six to eight weeks each. The sampling of teams was purposeful and also pragmatic (Suri, 2011) in that the local authorities and/or Trusts were those with which the research team already had connections due to previous research or teaching relationships. Having said this, they demonstrated wide variety in both geographies and populations, with both rural and urban communities represented, as well as diverse communities and those with high levels of child poverty. Team dynamics were observed and social workers were accompanied on their journeys where it was anticipated that they would be communicating with children, young people and their families. Wherever possible, social workers' expectations of the encounter were recorded in an audio interview en route to the visits and their reflections on the encounters recorded immediately afterwards. These interviews generally took place in the car but sometimes on foot. With permission, the researcher observed the communicative encounter, taking detailed observational notes.

Data analysis was undertaken systematically and mainly inductively developed from the data (Shaw and Holland, 2014). Analysis was also informed by the literature and by the team's history of engagement with social work practice and research. A coding frame was developed by the whole team, working on a small number of transcripts and observation notes together until all thematic codes were agreed. For 
this paper, a framework analysis was also used (Richie and Spencer, 1994; Gale et al., 2013). This is a process for categorising, displaying and analysing large datasets of qualitative data. All the visits were entered into an Excel database, with key features of the visit as variables (social worker characteristics, child and family demographics, nature, length and place of visit, if the child seen alone and people present in visit), allowing us to make systematic selections of data to illustrate points being made in the discussion of findings.

\section{The data set}

In total, 82 social worker encounters were observed in interactions with 126 children and young people ranging in age from babies who were a few months old to 17-yearold young people. As such this represents one of a growing number of similar data sets where social work practice during visits has been observed (Ferguson 2016; Broadhurst and Mason, 2014; Westlake, 2015; Killian et al., 2015). In this study, encounters ranged from 10 minutes to 270 minutes long; most were under an hour. In fifty per cent of the encounters, the child/young person was seen alone. In some cases, other children were present (0-5 other children), and in a small number of situations, older siblings who were young adults were also present. Over half of the social worker encounters took place at home (57\%) and around a quarter (24\%) took place in school. The remainder took place in public places (especially supermarket cafes) or specialist settings including social services buildings, a pre-booked library room, a hospital ward, a police child protection unit and secure accommodation. Hence while it remains a common assumption that social worker visits occur mainly within the family home (Ofsted, 2011), in reality and for a number of reasons there is great variety in the location of the visits; and second, while social workers are urged 
to see a child alone (Ofsted, 2011) this, for a variety of reasons as indicated above, may not be achievable or realistic.

The heterogeneity in the data set was further highlighted in relation to the purpose of the visit where these were conducted for a range of reasons - child protection investigations, assessment and family support. In the UK, the wider focus on child protection social worker visits that has dominated debates (Munro, 2010, 2011, a, b) and set agendas for reform (DfE, 2014) has rendered other types of social worker visit, in particular those occurring as part of family support, almost invisible and yet the current study indicates that first a number of such visits occur and that with a focus on support rather than investigation is likely to influence the communicative encounter that ensues. Another notable feature was the gender balance of the workforce where most social workers were women, with only $17 \%$ being men but where their length of professional experience ranged from 6 months to 17 years. A similar profile has been noted in other related studies (Ferguson, 2016; Killian et al., 2015). The detailed findings are now reported under each of the four research questions.

\section{What are social workers observed to do when they communicate and engage with children and young people?}

Making connections

An important finding to emerge was not so much that social workers made connections with children (which they did) but rather how they went about doing this. Findings revealed that some social workers employed a number of highly developed verbal and non-verbal skills to make connections with children. These included 
reflecting together on a shared memory of a previous visit, use of compliments and the intricate weaving of 'safe' topics of discussion with the more challenging aspects. Several of these aspects are illustrated in the one conversation below:

The SW puts her hand close to Clare's hand and points with her finger to Clare's nail varnish and says 'pretty'. Clare smiles. SW says 'and what about you, what sort of things do you like doing, you were playing with play-doh when I last visited weren't you?' Clare smiles and fidgets and says yes. Clare thinks and says that she likes school. SW asks her what she likes about school and Clare tells her about her friends, and how she likes playing with them. SW listens for a while. When the conversation finishes, SW pauses and asks Clare 'now, can you tell me what a worry is'. Clare pauses and says 'no' and giggles shyly.

Building on this and in the example below, the social worker illustrated how they have held the child in mind prior to the visit by thinking deeply about how the child might feel in the forthcoming meeting (anxious and fearful) and what strategies might help to secure their engagement:

I remember going to one school and the headmistress said to me, and the police officer, you won't get anything out of her because [...] she doesn't talk to anybody except her classroom assistant and [...] she's got learning needs [...] And when I went in there, sure as eggs is eggs, you know she wouldn't talk to me or the police officer, it was two men which was unfortunate $[\ldots]$ and we couldn't get anything and then I said to her, 'just tell me - are you happy or 
sad, look at my socks' [...] I had Mr Men socks on [...] I'd purposely put them on that morning, it was like I had an intuition and I put on an odd pair so that I had Mr Happy on one foot and Mr Sad on the other. And I said to her you know 'which do you feel, Mr Happy or Mr Sad?' And she burst out laughing and said I feel happy, then that was it, she was away.

These examples illustrate the social workers' use of the personal self in making connections with the child concerned and the importance of the social worker paying careful attention to the particularities and personality of the child.

\section{Moving with the child}

Ferguson's research (2016) demonstrated that social workers are mobile individuals. Findings from the current study support the idea that social workers are mobile, active and interactive but also take this notion a stage further to suggest that the mobility is not only physical but verbal and relational in that social workers change their position (confidante, adviser, messenger) to form connections as well as changing how, what, when and where they convey their communicative encounters. In the example below and while the social worker performed her statutory duty to check the bedrooms, she weaved into the encounter humour and empathy and positioned herself as the children's 'playmate' as the bedroom checking was underway:

The SW then asks whether it would be okay to see the bedrooms and then turns to Yale and asks him to show her how well he can walk up the stairs and for him to show her the bedrooms. We head up the stairs [...]. We look into 
Yale's bedroom [...] whilst Yale climbs into the wardrobe. The SW asks in a loud voice if we are playing hide and seek. Yale giggles and climbs out of the wardrobe. SW and Gideon play at this for three times and then the SW asks Yale if he can show her his sister's bedroom'

In the next example, the social worker engaged with a very young baby through movement and touch. She got down onto her knees, she held the baby's arms, and she moved her arms with the baby's arms:

The worker goes onto her knees and sits directly in front of Margaret and Chris [mum and child] and says 'can I touch'? [meaning can she touch Chris] to Margaret who nods 'yes, yes'. The worker speaks in a gentle, high pitched tone whilst gently squeezing Chris's arms speaking directly to Chris's face saying 'hello, hello'. Chris smiles and moves his head around. The worker squeezes up and down his arms and then takes his hands in hers, speaking to Chris all the while $[\ldots]$

These two examples highlight the social workers' capacity to adapt to the different situations they find themselves in and also draw attention to the very personal, physical and intimate nature of the encounters - a refreshing change from the dominant discourses around social workers' non-engagement with young children. The sensitive qualities and responsive, respectful processes that shaped the encounters could be described as child centred, contingent and contextual. 
The current study revealed that some social workers engaged with children using a number of methods and skills in the course of visits. These included (but were not limited to) drawing and colouring, Lego and arts and crafts based methods, as well as more specialist tools. In some conversations the activity was aligned with the purpose of the communication (for example both social worker and child constructing a genogram together to explore details of family members). On other occasions the social worker engaged in a range of play-based activities, which acted as a vehicle through which a conversation about something unrelated could then take place. In the next example, the use of methods facilitated and enabled the child to engage in a difficult conversation. Through the use of a pot that contained beads and elastic, the social worker established rapport and put the child at ease by inviting the child to make bracelets together. During this activity, and after a long 'lead in' where the two had made bracelets together, the social worker then introduced herself, her role and established the purpose of the meeting 'So biting, is that right?'. The conversation then continued while the activity changed to the use of Lego stored in a box as indicated below:

As they rummage through for pieces and Crystal builds it, the worker says 'so, when you have bitten?' and Crystal interrupts and says '(name of brother)'. FP says 'yes' and says that it has happened lots of times now. Crystal says 'yes'. She does not appear to be embarrassed or shy and they continue building the Lego and looking for the pieces and talk in the same style and tone when they talk about this. FP asks her when she does it. Crystal says that she bites her brother at mummy's house. The worker asks her if she bites at daddy's house. Crystal says no because she gets told off there [...] 
Findings from the study revealed that where methods were used, it was not so much that they were used (although this is very encouraging) but rather how they were used. Importantly the planned and personalised nature of the encounters helped provide a safe context for the communicative encounter to unfold - a key task social workers are tasked with undertaking (Ofsted, 2011, p. 7). Second, was an awareness that what was being observed in the private sphere of the visit appeared to remain largely invisible in the public domain. For example, researchers were aware that social workers rarely recorded the detailed content, nature and quality of their communicative encounters partly because of workload issues and partly because this was not overtly encouraged as part of normative practice. The structure of the case file record forms, for example, did not ask for commentary on the processes and quality of relational encounters (that might include reference to touch,

play, humour) but rather tended to reflect bureaucratic norms (a brief record indicating that the child was seen). Third, the researchers in this study were also aware that there were also occasions when social workers did not appear as skilled and were less able to use communication methods other than talking. A wider lack of attention and access to training opportunities and even to basic play materials was noted alongside these observations with even colouring pens and paper appearing to be missing from some offices.

\section{How do practitioners experience and understand their communication with a} child?

Findings reveal some interesting contradictions in the difference between what social workers understand and what they experience in their communicative encounters. 
Social workers understood that communication with children was a central and core aspect to their work as highlighted in field notes below:

As we walk across to the car she says she always carries lots of things around with her as she is thinking what might they like to do which is going to help them trust her and to feel comfortable. She opens her car-boot and there are puppets and toys and boxes with paper in them in there. I say that I haven't seen a SW with that amount of toys and things before and she says that she can't imagine how people go about talking to children without them.

Social workers also understood the purpose of it in terms of safeguarding children and ensuring their right to express their views is upheld:

Detailed direct work is what it's about [...] If [...] there's a child with a bruise you talk to a child on their own, you have to, you know it's essential to keep that child safe so again it's about, it's about making judgements and working out the best times and the best way trying to ascertain that voice

Despite this, social workers appeared to experience their communication with children and young people as challenging for a number of reasons including structural factors (work overload and office space); practice-related factors (unrealistic expectations connected with some of the visits) and personal factors (their own preferences and levels of confidence and the personal emotional impact of the encounters). Each is considered in turn. 


\section{Structural factors}

With regards to workload pressures the findings of this study are similar to others in highlighting the challenges for social workers in managing their workloads (Broadhurst et al., 2010; Featherstone et al., 2014). In the interview excerpt below, the social worker describes the experience of work overload to the point where she ceased to feel effective:

$[\ldots]$ you know those old fashioned meat grinders? That's how I see it [...] you put in a few assessments [...] and you turn the handle and everything comes out and you start completing and they put a few more in and its starts to sort of clog up a bit and then they chuck a few more in and then you get to the point where you can't move it because there are so many calls coming in, there's so much, just [...] juggling so many cases that you just stop, you just become ineffective, you think well where do I start? [...] sometimes you just think [makes sound] its just too much.

A related structural finding from field notes was the impact of office space on working relationships and on the organisation of social worker visits. In some offices 'hot desking' (also known in the literature as 'agile working' practices) had been adopted with the result that social workers did not have a desk or workspace that they could call their own. This combined with difficulties getting a car parking space at the office building resulted in social workers planning sequences of visits to run one after the other which then, on top of space and parking issues, resulted in social workers spending less time together as a team. Others teams did have allocated desks and car park availability. In some of these teams, researchers noted that social workers offered informal support to each other through sharing food as well as sharing 
discussions about their cases, their private lives and their relationships with other professionals.

\section{Practice related factors}

Practice that privileges bureaucracy over relationships runs counter to another contemporary trend in social work, that is, the relational aspects, which is accompanied by an increased expectation that social workers will communicate with all children and that they will do this effectively. However, the findings from this study suggest that such expectations need to be tempered with realistic understandings about what is achievable. This was highlighted in two areas of the job; first, in initial response teams where the very nature of the initial assessment role meant that the social worker would only see the child once or twice before passing the case on to another longer term team; and second, in the case where children had multiple professionals involved and where they have already had to 'tell their story' on many previous occasions. Some social workers queried the ethics of social workers practice where it was always assumed that communication was appropriate and necessary and felt that trying to establish deep and trusting relationships in some contexts was disingenuous as indicated in the example below:

You know actually sometimes they've [teenagers] already been spoken, especially as I said like rapes and things like that you know and they've been spoken to by the police, and they've been spoken to by the [child protection] officer [...] and actually quite often what I do is I say actually I don't want you to tell me the whole story again unless you really want to because you don't need to. 
These issues draw attention to the fact that is not always reasonable or right to expect children and young people to strike up meaningful communicative encounters with professionals.

\section{Personal factors}

Another overlooked area is social worker preferences in relation to working with children and young people. This has the potential to have an impact on communicative encounters as indicated in the examples below:

I think I've always preferred to work with teenagers because that's how I work and they're more likely to tell me what's happened and we see what we can do about it. But so especially primary school aged children they make me a little bit more like ahhh! [...]

On the other hand, another social worker said 'Um...I think I prefer the younger ones because that's more within my comfort zone'. These examples highlight that the increased demand for social workers to engage in relationship based work may need to be coupled with opportunities for social workers to be 'true to self' in terms of exploring their preferences, values and the impact of these on communicative encounters. This is important because research indicates that job satisfaction and efficacy are highest and burn out levels at their lowest when personal and professional values are aligned (Tartakovsky, 2015). Personal and professional value alignment is of particular relevance, for example, in terms of the requirement of 
social workers to see children alone. While they understood this requirement, some felt uncomfortable about being alone with children. For example, a male social worker was observed standing at the bedroom door of a first visit to a teenage girl who was sitting on her bed. There was no other furniture in the room and it may have felt intrusive for him to ask to sit with her on her bed. Other social workers, although not all, perceived very young children as being too shy to be seen alone, or that this might cause distress. Space and support to acknowledge and express these personal preferences and challenges appears to be important in that, unresolved, these issues may cause a source of anxiety which could affect the quality of other communicative encounters. The examples above all draw attention to the fact that how social workers understand and experience their communicative encounters is shaped and informed by a number of discourses that operate at the organisational, practice and personal levels. These discourses are not static but are contingent, context specific and shaped further by temporal and spatial factors.

\section{How do children experience and understand their relationships with social workers?}

We did not interview children and young people in phase one of this study. However, through observation, watching and listening to children's responses to, and the nature, level and types of, engagement with their social worker it was possible to see that children and young people had a range of understandings and experiences about their communicative encounters with their social workers. Some children and young people appeared to experience their social worker negatively as a threat, a stranger, a threat, an intruder, the enemy. Sometimes these responses could be connected with the fact that the children did not understand who the social worker was as alluded to below: 
Sometimes they don't want to talk to you and that in itself is sometimes part of the assessment actually they're really reluctant to me, is that because they're frightened or scared or they've been told by Mum actually the social workers coming to see you so don't you dare say anything.

The varying experiences and understandings of the social worker led to children and young people responding with shyness, indifference, hostility and spirited resistance to their involvement. In one family, and in response to the social worker visit to an older sibling of a disabled child on the child protection register, the young person angrily said to her mother who had been asked for a family update:

Don't tell them! They don't need to fucking know!

It was equally the case, however, that the social worker was welcomed into people's homes and other venues where meetings took place. On these occasions, the social worker was observed to be understood and experienced by children and young people as a visitor, a friend and a source of support. In the example below the field notes indicated that the family had gathered together in the front room awaiting the arrival of their special and welcome visitor - the social worker, who they then took turns to entertain. Seamus [the child - aged 10 years] was engaged in a discussion about school. The researcher recorded:

The social worker then says 'and is your [school report] good too Seamus?' [...] Seamus laughs, jumps up out of his seat and mimics reluctantly carrying 
a battered report home to his mum. The family members and the social worker laugh out loud. Seamus jumps up and down a couple of times, does a fake bow and then takes his seat again. He has a wide grin on his face.

In the next example, the social worker (and indeed the researcher) had been engaged in a lengthy conversation with Reece about the intricacies of a computer game that is of great enjoyment to him. It was time to go and the researcher filed notes indicate how Reece views his social worker as his friend:

The social worker says 'look Reece [10-year-old child], we have to go now' [...] Reece comes out of his room really quickly and says 'don't go, don't' go'. The social worker says 'oh Reece we have to go' [...] At this Reece throws his arms around the social worker giving her a big hug and a squeeze. 'I don't want you to go'. The social worker reciprocates with a hug (not of the same size and strength of Reece's)

\section{What factors are most helpful in facilitating communication?}

In addressing this question our findings indicate that given the complex, contingent and context context specific nature of communicative encounters it is impossible to create a definitive list of factors that facilitate communication. Each encounter is: unique to the individuals involved; formed within and shaped by a particular time and space; and informed by broader social, economic, political contextual considerations that position children, families and the professional practices of social workers in particular ways. These broader themes are returned to in the subsequent discussion. 
As a precursor, however, it is worth highlighting three issues that the study did highlight as helpful namely: the reflective practitioner; the use of self; and the emphasis on context.

With regards to the reflective practitioner this study highlighted the personal benefit that some social workers said they had derived from having a researcher who was embedded in their team and who accompanied them (usually in their cars) on their way to visits and on their way back from visits. The researcher-social worker communicative encounters that usually took place in cars on the way to and back from visits, may, in an important sense, have mirrored Ferguson's findings regarding children's communication with social workers in that for both, the common theme was that the car provided a 'safe space' to talk - it was uninterrupted and allowed for deep discussion without eye contact. One of the researchers noted that on several occasions, conversations that began after a visit on the way back to the office then continued long after arrival back into the car park. Furthermore, the experience of having the space to reflect immediately after a visit produced for some social workers a 'light bulb' moment in terms of deepening their own insight into the dynamics of the communicative encounters and what might help. The presence of a researcher thus provided a sounding board, allowing for the articulation of thoughts emerging from the observation, which then turned, for the social worker, into a plan of action.

Related to this use of self was highlighted in this study as a concept that has not been fully engaged with or operationalised in professional practice in this area. Use of self requires being aware of one's own personal qualities, professional attributes 
and alignment with professional responsibilities. Fully realised in practice, this would involve social workers being able to be open and honest about their personal preferences, their likes/dislikes, their strengths and weaknesses, their intimate and distant relationships with children and families. These qualities do not sit well with the bureaucratic and technical model which, while being re-shaped, still pervades practice to a significant extent.

A third helpful theme is the centrality of context. At the risk of stating the obvious, relational social work does not occur in a vacuum but in a context/contexts - these could include the relational, social, environmental, psychological, cultural contexts. Communication is continuous in the sense that the meanings derived from a communicative encounter may go on long after the encounter has finished. Communication is contingent, dynamic and fluid. Each communicative encounter is therefore unique and can never be fully replicated. At its simplest if the same social worker delivers the same message to the same family twice there will be components in each of these encounters that are different whether these be from the child, the case, the social worker and/or the context(s). These issues highlight the need for a model of communication within social work practice that acknowledges the complexity and contingent nature of communicative encounters and that factors this into training and practice.

\section{Discussion}

Models of communication are divided into four main types: linear; interactive; transactional and ecological. Whereas the linear model focuses on the acts of delivering and receiving messages (Lasswell, 1948), the interactive (Schramm, 
1955), transactional and ecological models (Altheide, 1994) situate both the recipient and messenger as communicators and also locate communicative processes in their wider contexts. The ‘ecology of communication' model (proposed by Altheide, 1994) is useful, within the context of this study and these findings because, as opposed to the organisation of communication for example, the ecology of communication 'implies relationships related through process and interaction. Second, ecology implies a spatial and relational basis for a subject matter [...] Third, the relations are not haphazard or wholly arbitrary; connections have emerged that are fundamental [and] Fourth, there are developmental, contingent and emergent features of ecology. The interdependence suggests that a change in any portion of the process is likely to influence another portion'. These distinguishing features of the 'ecology of communication' (Altheide, 1994, p. 667). He goes on to state that 'the concept "ecology of communication" is grounded in the search for meaning, rather than causation or technological determinism' (Altheide, 199, p. 667). These distinguishing features best begin to explain some of the findings this article has mapped out.

in this article the ecology of communication is depicted by four overlapping filtering lenses: the child; the case; the social worker; and the context (see Figure 1). On one level this is a very straightforward model. However, its complexity soon becomes apparent in that within each lens exist a number of potential variables that might influence and shape the nature and quality of the communicative encounters. For example, in relation to the child communicative encounters might be shaped by their: like/dislike of the social worker; mood that day; experiences of abuse, trauma, poor attachment relationships; and their understanding of the social worker role. These 
are but a few variables, the list for each lens being as endless as the configuration, degree of overlap and interaction between each.

Related to the findings the model suggests that far from children being passive receivers of social worker messages they, like adults, can detect genuineness, in terms of interest in, and value attributed, to hearing their feelings, views and thoughts. Our findings also suggest that social workers need to feel able to respond openly and flexibly, rather than trying to fit themselves (and the young person) into a particular approach that is the current de rigueur in social work. Furthermore, addressing the child and case related issues requires social workers to have considerable confidence in responding to the child or young person in-the-moment and that they need to be adaptable, capable of having a range of activities and equipment to hand, yet prepared to abandon them, if required, in order to join in with the child's activity.

Beyond this the findings indicate that while communication skills and methods are important, they are only insofar as the context of the actual encounter between the child or young person and the social work practitioner allow. Significantly, the findings have demonstrated that social work practice with children and families can take place in difficult, constrained environments. Social work involvement, even when requested or welcomed, can be viewed with suspicion; whilst a heavy caseload, bureaucratic demands, and the lack of opportunity for direct work can lead to disappointed expectations and an intrusion in family life that often carries no (perceived or real) benefit for children or families. 
Despite these constraints, the findings also revealed social workers trying to work out the best way of connecting with children, talking with them, listening to them, explaining what was happening and why. Often, and reflecting contextual normative bureaucratic discourses it was these very aspects of relational practice that were the least visible to colleagues and on case records. Furthermore, it was the nuanced, intricate nature and quality of these communicative encounters that were the least articulated and written about. Lastly the findings suggest that while there are aspirations towards more face-to-face practice and the foregrounding of its relational dimensions (Ruch et al., 2010; Ruch, 2014; Broadhurst and Mason, 2014), these sometime struggle to find traction because of contextual factors where bureaucratic requirements dominate.

\section{Funding statement}

This research study is funded by the Economic and Social Research Council. Grant Ref: ES/K006134/1 Communicating with Vulnerable Children: Understanding the Everyday Practices of Child and Family Social Workers

\section{Acknowledgements}

The research team would like to thank the families, children and social workers that took part in this study and the reviewers for their helpful and constructive comments.

\section{References}

Altheide, D. L. (1994) 'An ecology of communication', The Sociological Quarterly, 35, pp. 665-683. 
Winter, K. (2011) Building Relationships and Communicating with Children. A Practical Guide for Social Workers, London, Routledge.

Broadhurst, K, White, S, Fish, S, Munro, E, Fletcher, K and Lincoln, H. (2010) Ten Pitfalls and How to Avoid Them, London, NSPCC.

Broadhurst, K. and Mason, C. (2014) 'Social work beyond the VDU: Foregrounding co-presence in situated practice-Why face-to-face practice matters', British Journal of Social Work, 44(3), pp.578-595.

Department for Education (2014) Children's Social Care Innovation Programme. Ref: DFE-00379-2014, London: Department for Education.

Featherstone, B, White, S, Morris, K and White, S. (2014) Re-Imagining Child Protection: Towards Humane Social Work with Families, Bristol, Policy Press.

Ferguson, H. (2009) 'Performing child protection: home visiting, movement and the struggle to reach the abused child', Child and Family Social Work, 14(4), p. 471-480.

Ferguson, H. (2016) 'Researching social work practice close up: Using ethnographic and mobile methods to understand encounters between social workers, children and families', British Journal of Social Work, 46(1), p. 153-168. 
Haight, W, Kayama, M and Korang-Okrah, R. (2014) 'Ethnography in social work practice and policy', Qualitative Social Work, 13(1), p. 127-143.

Killian, M, Forrester, D, Westlake, D and Antonopoulou, P. (2015) 'Validity of the working alliance inventory within child protection services', Research on Social Work Practice, 1049731515596816, first published on July 27, 2015.

Laming, H. (2003) The Victoria Climbié Inquiry: Report of an Inquiry by Lord Laming, Cmnd 5730, London, HMSO.

Laming, H. (2009) The Protection of Children in England: A Progress Report. Vol. 330, London, HMSO.

Lasswell, H.D. (1948) 'The structure and function of communication in society', The Communication of Ideas, 37, p.215-228.

Lefevre, M. (2013) 'Integrating the teaching, learning and assessment of communication with children within the qualifying social work curriculum', Child and Family Social Work, 20(2), p. 211-222.

Luckock, B and Lefevre, M. (2008) Direct Work: Social Work with Children and Young People in Care, London, British Association for Adoption and Fostering.

Office for Standards in Education, Children's Services and Skills (Ofsted). (2011) The Voice of the Child: Learning Lessons from Serious Case Reviews. Reference no: 100224, Manchester, Ofsted. 
Munro, E. (2010) The Munro Review of Child Protection - Part One: A Systems Analysis, London, Department for Education.

Munro, E. (2011a) The Munro Review of Child Protection Interim Report: The Child's Journey, London, Department for Education.

Munro, E. (2011b) The Munro Review of Child Protection: Final Report: A Child Centred System, London, Department for Education.

Richie, J and Spencer, L. (1994), 'Qualitative data analysis for applied policy research', in Bryman and Burgess (eds.) Analysing Qualitative Data, London: Routledge, p173-194.

Ruch, G. (2007) 'Reflective practice in contemporary child-care social work: the role of containment', British Journal of Social Work, 37(4), pp.659-680.

Ruch, G., Turney, D. and Ward, A. (2010) Relationship-Based Social Work: Getting to the Heart of Practice, London, Jessica Kingsley Publishers.

Ruch, G. (2014) 'Helping children is a human process': researching the challenges social workers face in communicating with children', British Journal of Social Work, 44(8), pp.2145-2162.

Schramm, W. (1955) 'Information theory and mass communication', Journalism \& Mass Communication Quarterly, 32(2), p.131-146. 
Shaw, I.G.R and Holland, S. (2014) Doing Qualitative Research in Social Work. Sage.

Suri, H. (2011) 'Purposeful Sampling in Qualitative Research Synthesis', Qualitative Research 11(2), pp.63- 75.

Warner, J. (2015) The Emotional Politics of Social Work and Child Protection, Bristol, Policy Press.

Winstanley, S and Hales, L. (2015) 'A preliminary study of burnout in residential social workers experiencing workplace aggression: Might it be cyclical?', British Journal of Social Work, 45(1), p. 24-33. 